\title{
THE DIAGNOSIS OF PREGNANCY AND ESTIMATION OF FOETAL NUMBERS IN SHEEP BY LAPAROSCOPY
}

\author{
M. PHILLIPPO, * G. H. SWAPP, $\dagger$ J. J. ROBINSON* AND J. G. GILL* \\ *Rowett Research Institute, Bucksburn, Aberdeen, and \\ $\uparrow$ Aberdeen Royal Infirmary, Foresterhill, Aberdeen
}

(Received 1st April 1971)

\begin{abstract}
Summary. The genital tract was examined by laparoscopy in anaesthetized sheep at various intervals after mating. A positive diagnosis could be made as early as the 17th day after mating. A correct diagnosis of pregnancy was made in twenty-eight out of thirty-one ewes and the diagnosis of non-pregnancy was correct in twenty-one out of twentythree ewes. The number of lambs carried was correctly estimated from the number of corpora lutea in twenty out of twenty-four ewes. The results of the method are comparable to those reported by other methods of pregnancy diagnosis in the ewe.
\end{abstract}

The most reliable results reported for the diagnosis of pregnancy in the ewe are from radiographic techniques but these are inadequate before the 50th day of pregnancy (Ford, Clark \& Gallup, 1963; Ardran \& Brown, 1964). Ultrasonic techniques (Fraser \& Robertson, 1968; Hulet, 1969; Wilson \& Newton, 1969; Lindahl, 1969, 1970) have a poor success rate before the 70th day of gestation. Laparotomy (Lamond, 1963; Cutten, 1970) has been used between the 28th and 60th days to diagnose pregnancy but may interfere with the fertility of the ewes examined (Cutten, 1970). Examination of the abdominal cavity using an endoscope has been used extensively in human gynaecology and Roberts (1968) has used the technique for examination of the genital tract of the ewe, without publishing any observations on pregnancy diagnoses. It was considered worthwhile to explore the application of the technique of laparoscopy to the diagnosis of early pregnancy in sheep since it involves less surgical interference than laparotomy.

Fifty-four Dorset Poll, Cheviot and Blackface ewes were used. They were removed from the flock between 6 and $24 \mathrm{hr}$ before the operation, during which time they received neither food nor water. Examination was facilitated if the animal was made to empty the bladder by inducing a slight degree of anoxia before anaesthetization. Anaesthesia was induced with intravenous thiopentone sodium ( $20 \mathrm{mg} / \mathrm{kg}$ body weight), and maintained with an oxygen-fluothane mixture in closed-circuit. A Frangenheim fibre-light laparoscope with a $180^{\circ}$ telescope was used routinely under fully sterile conditions.

The animals were placed on their backs and tilted head down to an angle of $30^{\circ}$ from the horizontal to assist movement of the viscera away from the posterior region of the abdominal cavity. A small (15-mm) incision was made 
through the skin and subcutaneous fascia of the ventral abdominal wall approximately 5 to $6 \mathrm{~cm}$ anterior to the mammary gland and $3 \mathrm{~cm}$ from the mid-line to avoid any mammary veins. The peritoneal cavity was filled through a small cannula with about 4 litres of carbon dioxide from a standard anaesthetic apparatus at 2 litres/min. An $11-\mathrm{mm}$ diameter trocar and sleeve were then inserted towards the animal's pelvic rim, the trocar was withdrawn and the laparoscope inserted. Another smaller incision was made in an identical position on the opposite side of the mid-line for the insertion of the Palmer biopsy forceps which were used to elevate the genital tract and bring the ovaries into view. The number of corpora lutea, their size and form, and the number and size of any ovarian follicles were recorded. The degree of distension of the uterus and the arrangement of the blood vessels on its surface were also noted. After the examination, the incisions were closed with Michel clips and the animals recovered uneventfully within $10 \mathrm{~min}$.

TABLE 1

DIAGNOSIS OF PREGNANGY AND ESTIMATION OF LAMB NUMBERS

\begin{tabular}{|c|c|c|c|c|}
\hline & & \multicolumn{3}{|c|}{ No. of lambs born } \\
\hline & & 0 & 1 & 2 \\
\hline $\begin{array}{l}\text { No. of lambs predicted } \\
\text { from number of corpora lutea } \\
\text { observed in both ovaries }\end{array}$ & $\begin{array}{l}0 \\
1 \\
2\end{array}$ & $\begin{array}{r}19 \\
2 \\
0\end{array}$ & $\begin{array}{r}2 \\
11 \\
1\end{array}$ & $\begin{array}{l}0 \\
3 \\
9\end{array}$ \\
\hline $\begin{array}{l}\text { Diagnosis based on } \\
\text { uterine morphology }\end{array}$ & $\underset{\mathbf{P}}{\mathrm{NP}}$ & $\begin{array}{l}2 \\
1\end{array}$ & $\begin{array}{l}0 \\
2\end{array}$ & $\begin{array}{l}0 \\
2\end{array}$ \\
\hline
\end{tabular}

$\mathrm{P}=$ pregnant; $\mathbf{N P}=$ non-pregnant.

Initially, diagnosis was undertaken in animals which had been mated between 20 and 40 days previously. During the course of the work, it was found that the uterine enlargement often precluded adequate examination of both ovaries and later work was confined to animals mated 17 to 28 days before surgery.

The results of the study are summarized in Table 1. Pregnancy was correctly diagnosed in twenty-eight of thirty-one $(90.5 \%)$ ewes and non-pregnancy in twenty-one of twenty-three $(91.5 \%)$. One of the three incorrect diagnoses of pregnancy was based upon the uterine morphology alone, whilst the other two diagnoses related to animals that had been mated out-of-season after hormonal treatment. In one of these ewes, foetal loss must have occurred as the presence of a foetus had been ascertained at a subsequent laparotomy operation. The fact that the diagnoses were made during early pregnancy when embryonic death can occur (Quinlivan, Martin, Taylor \& Cairney, 1966) might explain the other discrepancy. The two false negative diagnoses resulted from a failure to observe a corpus luteum in one of the ewes and a confusion between a deeplying corpus luteum and a follicle in the other: both of these ewes were examined at the 20 th day after mating.

The number of corpora lutea gave a correct estimate of the number of lambs carried in twenty out of twenty-four pregnant ewes in which both ovaries were 
examined. In three of the remaining four ewes, the number of lambs exceeded the number of corpora lutea observed. This discrepancy was probably due to a failure to detect all the corpora lutea present.

It was found that diagnosis was more difficult in heavy ewes $(>70 \mathrm{~kg})$ with a large amount of omental fat, and the number of occasions on which both ovaries were observed in such ewes was reduced (fourteen out of twenty compared to ten out of eleven). In heavy animals, the time taken for the examination was usually around $20 \mathrm{~min}$ whereas in lighter animals the time was only 8 to 10 $\min$.

The present data were compared with the results from other techniques by means of the $\chi^{2}$-test. There was no difference between the techniques of laparoscopy and laparotomy (Cutten, 1970) in the diagnosis of pregnancy before the 28th day of pregnancy. The laparoscopy technique did not affect the number of ewes that subsequently become barren as has been reported to occur after laparotomy (Cutten, 1970). The overall results of the ultrasonic techniques of Fraser \& Robertson (1968), Hulet (1969), Wilson \& Newton (1969) and Lindahl $(1969,1970)$ were not significantly better than our own results with the exception of the Doppler technique of Lindahl (1969). At early stages of pregnancy, however, the ultrasonic techniques were unreliable: our own results were, for instance, more reliable than those reported by Wilson \& Newton (1969) for ewes examined before the 69th day of pregnancy $\left(\chi^{2}=23.44, P<\right.$ $0 \cdot 001$ ). The radiographic techniques (Benzie, 1951; Ford et al., 1963; Ardran \& Brown, 1964) gave a higher accuracy than laparoscopy for the diagnosis of pregnancy as such although these techniques have mainly been concerned with the determination of foetal numbers. Attempts at predicting lamb numbers between the 51st and 70th days of pregnancy (Ardran \& Brown, 1964) were significantly less reliable than our results $\left(\chi^{2}=20 \cdot 75, P<0.001\right)$. There were no significant differences between the present method and radiography carried out after the 70th day of pregnancy (Ford et al., 1963; Ardran \& Brown, 1964) in predicting lamb number despite the early stage of pregnancy at which laparoscopy was undertaken.

The technique described here provides a practical method for the diagnosis of pregnancy between the 17th and 28th days of pregnancy. It takes longer to perform than the radiographic and ultrasonic techniques, but the results are comparable in most instances and it is of equal value in determining the number of lambs.

We are indebted to Mr L. E. Vowles, Mr D. R. Donaldson and Mr M. Smith for their invaluable assistance during this work.

\section{REFERENCES}

ARdran, G. M. \& BRown, T. H. (1964) X-ray diagnosis of pregnancy in sheep with special reference to the determination of the number of foetuses. F. agric. Sci., Camb. 63, 205.

BenzIE, D. (1951) X-ray diagnosis of pregnancy in ewes. Br. vet. $\mathbf{7 . 1 0 7 ,} 3$.

CUTteN, I. N. (1970) Immediate and long-term effects of post-mating laparotomy on the lambing performance of Merino ewes. Proc. Austr. Soc. Anim. Prod. 8, 388.

Ford, E. J. H., CLARK, J. W. \& Gallup, A. L. (1963) The detection of foetal numbers in sheep by means of X-rays. Vet. Rec. 75, 958. 
Fraser, A. F. \& Robertson, J. G. (1968) Pregnancy diagnosis and detection of foetal life in sheep and pigs by an ultrasonic method. Br. vet. F. 124, 239.

Hulet, C. V. (1969) Pregnancy diagnosis in the ewe using an ultrasonic Doppler instrument. F. Anim. Sci. 28, 44 .

Lamond, D. R. (1963) Diagnosis of early pregnancy in the ewe. Austr. vet. F. 39, 192.

LiNDAHL, I. L. (1969) Comparison of ultrasonic techniques for the detection of pregnancy in ewes. $\mathcal{F}$. Reprod. Fert. $18,117$.

Lindahl, I. L. (1970) Intrarectal detection of pregnancy in ewes. (Abstract). F. Anim. Sci. 31, 225.

Quinlivan, T. D., Martin, C. A., TAYloR, W. B. \& Cairney, I. M. (1966) Estimates of pre- and perinatal mortality in the New Zealand Romney Marsh ewe. I. Pre- and peri-natal mortality in ewes that conceived to one service. F. Reprod. Fert. 11, 379.

Roberts, E. M. (1968) Endoscopy of the reproductive tract of the ewe. Proc. Austr. Soc. Anim. Prod. 7, 192.

Wilson, I. A. N. \& Newton, J. E. (1969) Pregnancy diagnosis in the ewe: a method of use on the farm. Vet. Rec. 84, 356. 